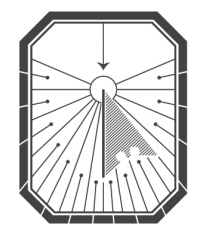

KYIV-MOHYLA

LAW \& POLITICS JOURNAL

KYIV-MOHYLA SCHOLARLY PEER-REVIEWED JOURNALS

\title{
An Essay on Legal Writing in Plain English
}

Author(s): Christopher R. Kelley

Source: Kyiv-Mohyla Law and Politics Journal 4 (2018): 175-193

Published by: National University of Kyiv-Mohyla Academy

http://kmlpj.ukma.edu.ua/ 


\title{
An Essay on Legal Writing in Plain English
}

\author{
Christopher R. Kelley \\ University of Arkansas, \\ School of Law
}

\section{Author's Note}

This essay is addressed to law students, lawyers, law professors, legislators, and judges who write in English. It offers tips on writing clearly, concisely, and engagingly in the plain English style. This is the style taught in U. S. law schools and in continuing legal education programs for U. S. lawyers and judges. And federal law requires federal agencies to use the plain English style when they write regulations and other public documents. It is offered here to encourage you to use the plain English style when your goal is to communicate efficiently and effectively.

\section{(2)}

Good lawyers are good communicators. Indeed, probably no other attribute is more essential to a lawyer's success. ${ }^{1}$ As this is particularly true of lawyers' writings. Ruth Bader Ginsburg, an Associate Justice on the United States Supreme Court, acknowledged this when she observed:

Lawyers serve their clients best when their readers can quickly and firmly grasp their points. Readers of legal writing, on and off the bench, often work under the pressure of a relentless clock. They may lack the time to ferret out bright ideas buried in complex sentences, overlong paragraphs, or too many pages. Strong arguments can escape attention when embedded in dense of Delphic prose. Lucid, well-ordered writing can contribute immeasurably to a lawyer's success as an advocate and counselor. ${ }^{2}$

Justice Ginsburg's observation implicitly tells a truth about lawyers' writings: no one reads them for pleasure; they read them because they must. To serve their readers, therefore, lawyers should write so their readers "can quickly and firmly grasp" their points.

$1 \quad$ Scott E. Fruehwald, Legal Writing Exercises: A Practical Guide to Clear and Persuasive Writing for Lawyers (New York: American Bar Association, 2014), xi ("noting that [n]o matter how brilliant a lawyer's ideas may be, those ideas will remain unheard if the lawyer cannot communicate them effectively").

2 Ruth Bader Ginsburg, Forward to Bryan A. Garner, Garner on Language and Writing (New York: American Bar Association, 2009), xiii. 
The legal profession has known how to do this for centuries. In 1887, for example, an English lawyer wrote that good legal drafting "says in the plainest language, with the simplest, fewest, and fittest words, precisely what it means." 3 Yet, not all lawyers, probably most, do not adhere to this standard. Writing in 1993 when he sat on the United States Court of Appeals for the District of Columbia Circuit, Judge Harry T. Edwards complained, "In my twelve years on the bench, I have seen much written work by lawyers that is quite appalling. Many lawyers appear not to understand even the most elementary matters pertaining to style of presentation in legal writing..." 4

Little has changed. Consider this lament about contemporary legal writing: "Whoever the reader is [judge or law clerk], one thing is certain: run-of-the-mill brief writing is pretty bad. It's slow and dull and abstract and digressive. ${ }^{5}$

Perhaps part of the blame for this lies in the competing obligations lawyers face:

Legal writers face two competing obligations. They must do full justice to the complexity of their subject matter, no matter how torturous or ambiguous it is. Then they must transform all that complexity into a prose so lucid, so crisp and direct, that it will satisfy readers who demand absolute clarity when - in fact, especially when the subject is most obscure. ${ }^{6}$

Lawyers, however, should not be excused from writing well. Their readers need and deserve to read good legal writing. Good legal writing has three fundamental qualities: it is clear, concise, and engaging. ${ }^{7}$

Legal writing in plain English — or plain language writing — is a style of writing that fosters clarity and concision and strives to engage the reader. It is founded on a modest collection of basic principles, many of which are presented in this essay. This essay's goal is to introduce you to or remind you of these principles.

Improving lawyers' writing is an overdue, much-needed legal reform. Poor writing is costly: "people actually suffer from it. Not least among the sufferers are judges who must try to make sense out of nonsense. But the vexation that judges feel pales in comparison with the economic and emotional costs that clients often experience."

3 Bryan A. Garner, Garner on Language and Writing (New York: American Bar Association, 2009) (quoting J. G. Mackay, "Introduction to an Essay on the Art of Legal Composition Commonly Called Drafting," Law Quarterly Review 3 (1887): 290.

Harry T. Edward, "The Growing Disjunction Between Legal Education and the Legal Profession," Michigan Law Review 91 (1993): 34

Bryan A. Garner, The Winning Brief: 100 Tips for Persuasive Briefing in Trial and Appellate Courts, 2nd ed. (Oxford; New York: Oxford University Press, 2004), ix.

6 Stephen V. Armstrong and Timothy P. Terrell, Thinking Like a Writer: A Lawyer's Guide to Effective Writing and Editing, 3rd ed. (New York: Practicing Law Institute, 2009), 3.

7 Mark Osbeck, "What is 'Good Legal Writing' and Why Does it Matter?," Drexel Law Review 4 (2012): 417, 427 .

8 Bryan A. Garner, A Dictionary of Modern Legal Usage, 2nd ed. (Oxford; New York: Oxford University Press, 1995), 665 (defining "plain language"). 
Therefore, lawyers ought to improve their writing: efficiency and fairness demands this. Plain language writing is a good place to start.

\section{Omit Needless Words}

\section{A. Introduction-We Write for Our Readers}

1.1 As legal writers, our first obligation is to our readers. We write for our readers.

1.2 Our readers read our writing for information. Our writing should be interesting enough to hold our readers' attention, yet its primary task is to convey information clearly.

1.3 Our readers are busy. They want us to write clearly. They do not want to waste time being uncertain or confused about what we are telling them. And they want us to write concisely. They do not want to wade through words that do not tell them what they want or need to know.

1.4 Clarity and concision go hand in hand. Writing concisely means eliminating unnecessary words.

1.5 Consider $1 / 4$ versus $12 / 48$. Both express one-quarter. Which is clearer? Which is more concise?

1.6 Writing concisely, however, does not always mean using fewer words. Clarity sometimes requires more explanation, not less. Writing concisely means that each word should have a purpose. And it means choosing the right wordBthe word that does the most work with the greatest economy.

1.7 Professor Wydick tells us, "[a] well constructed sentence is like fine cabinetwork. The pieces are cut and shaped together with scarcely any glue. When you find too many glue words in a sentence, take it apart and reshape the pieces to fit together tighter." ${ }^{9}$

1.8 If you prefer an analogy to a sport instead of to cabinet making, imagine a tug-ofwar contest. In a tug-of-war contest two teams holding opposite ends of a rope try to pull the other team across a line that is midway between them at the contest's start. When each team is pulling hard, the rope is taut; it is stretched tight and has no slack. "Ideally, legal writing is taut." ${ }^{10}$ Good legal writing omits unnecessary words. In good legal writing, every word tells."1

$9 \quad$ Richard C. Wydick, Plain English for Lawyers, 5th ed. (Durham: Carolina Academic

Press, 2005), 7.

10 Bryan A. Garner, The Elements of Legal Style, 2nd ed. (Oxford; New York: Oxford University Press, 2002), 53 (telling legal writers that "[t]o tighten your style, try to cut one fourth of every sentence in your first draft. Strike out every slack syllable"). 


\section{B. Spotting Poorly Constructed Sentences: Working Words and Glue Words}

1.9 Wydick divides the words in a sentence into two categories: "working words" and "glue words." "The working words carry the meaning of the sentence." 12 The glue words "hold the working words together to form a proper, grammatical sentence."13 The writer's goal is to write sentences with more working words than glue words.

1.10 Wydick offers this sentence as an example of what he means:

A trial by jury was requested by the defendant.

Here is the sentence with its four working words italicized:

A trial by jury was requested by the defendant.

The sentence's other five words are glue words. This sentence has five glue words and four working words. The number of glue words is disproportionately high. Therefore, the sentence should be rewritten:

\section{The defendant requested a jury trial.}

The rewritten sentence has four working words and two glue words. And the sentence has been shortened from nine words to five words. It is now tighter and more forceful. ${ }^{14}$

1.11 You might have noticed that the original sentence "A trial by jury was requested by the defendant" is written in the passive voice. The actor in the sentence "the defendant" is not the sentence's subject. The subject of the sentence "a trial by jury" is not doing anything. By rewriting the sentence in the active voice "The defendant requested a jury trial" the sentence is shorter and more forceful. Two active voice virtues are shorter and more forceful sentences. More is said about the active voice and its virtues in part III.

1.12 Underling working words and comparing their number to the number of glue words in a sentence takes time. Still, as a method for improving your writing, comparing working words to glue words is useful. Over time, you will get better at eliminating surplus words.

1.13 The basic formula is this: Know what you want to say. Then say it in as few words as possible.

1.14 Typically our first drafts are too wordy because we are trying to write while we are still thinking about what we want to say. For instance, consider this sentence:

\footnotetext{
12 Wydick, Plain English for Lawyers, 7.

13 Wydick, Plain English for Lawyers, 7.

14 Wydick, Plain English for Lawyers, 7-8.
} 
It is to be noted that in this case the amended petition upon which the judgment was to be rendered for Smith was to recover a debt owing by the defendant arising from the purchase of the same oil and for the same prices as alleged in the original petition, and judgment was rendered for exactly the same sum as was sought to be recovered in both petitions.

This sentence contains 66 words. This alone makes it hard to understand.

What is the sentence trying to say? To answer this question, you might have to ask other questions. For instance, who is the plaintiff? Is it Smith? Yes. Why is Smith suing the defendant? Is the suit to recover the unpaid price for the sale of oil? How many times has Smith asserted her claim? Twice? Was the sum sought in the amended petition the same sum sought in the original petition? Which petition was the basis for the judgment?

Bryan Garner rewrites the sentence to read: "Notably, the debt that Smith recovered under the amended petition was the same debt as she sought in the original petition." ${ }^{15}$

Garner's sentence contains 21 words. Is it easier to understand than the original sentence? Why?

1.15 Garner reminds us that brevity should never sacrifice clarity. He gives this example:

A will is ambulatory in character and subject to change or revocation at any time.

What does "ambulatory" mean? Used as a legal term, ambulatory means capable of being changed or revoked. Since a will is ambulatory, is Garner's sentence redundant? Yes, but would this sentence be better: "A will is ambulatory?"

If you are writing to a client, can you be certain your client would know what "ambulatory" means in this context? Would this be a better way to rewrite the sentence: "A will may be changed or revoked at any time before the testator dies?" As Garner notes, "This revision uses more words but is more immediately comprehensible to many more readers." ${ }^{16}$ In short, be brief but also be clear.

\section{Compound Constructions}

1.16 Using compound constructions adds unnecessary words. For instance, "for the reason that" can be substituted by "because," thereby replacing four words with one word. Using "if" instead of "in the event" replaces three words with one word. And so on. Watch for compound constructions and avoid using them.

15 Garner, The Elements of Legal Style, 54.

16 Garner, The Elements of Legal Style, 54-55. 


\section{Focus on the Actor, the Action, and the Object}

1.17 When possible, avoid "it is," "there are," and the like. They waste words. And their use weakens your sentences.

Compare the following:

1a. There are two things wrong with...

$1 b$. Two things are wrong with...

2a. There is no rule that is more important.

2 b. No rule is more important.

3a. There is no case law that addresses the question.

3 b. No case addresses the question.

What is gained by using "there" (or "it") and a form of "to be"? What is lost?

1.18 You will write better if you often use subject-verb pairs, making the actor the subject. Thus, instead of "There were two reasons given by the court for its decision," write, "The court gave two reasons for its decision."

\section{E. Minimize Your Use of "Of"}

1.19 "The goal of concision and succinctness is to get the most thoughts in the shortest space to make every word tell. Write as if you will be paid more if you use fewer words." ${ }^{17}$

1.20 Every time you write "of" pause to consider whether you can avoid using it. "Of is a big part of the wordiness problem." 18 Here are ways to eliminate "of":

Use the possessive: The decision of the court is wrong.

The court's decision is wrong.

Rewrite: I am a fan of football.

I am a football fan.

As a result of

Because

Forty-six years of age

Forty-six years old

1.21 When you edit your writing, devote one round to eliminating "of." Your writing will improve.

\section{F. Write Positively}

1.22 Positive writing is easier to understand and often more concise. For example, instead of writing:

The decision was not wrong.

17 Gerald Lebovits, “'Of' With Their Heads: Concision,” New York State Bar Association Journal 64 (November-December 2001): 73 .

18 Gerald Lebovits, “'Of' With Their Heads,” 73. 
write:

The decision was correct.

1.23 When you write positively even negative consequences can be presented in a pleasant manner. For instance, compare:

If you do not pay your bill, we will not continue to represent you.

with:

Please payyour bill so we can continue to represent you.

1.24 Sometimes you must write negatively. Be concise when you do. Avoiding "not" will help, as the following comparisons illustrate:

\begin{tabular}{ll} 
wORDY & CONCISE \\
\hline did not have support & unsupported \\
\hline did not recall & forgot \\
\hline not apposite (not relevant) & inapposite, irrelevant \\
\hline not current & stale, outdated \\
\hline not important & unimportant \\
\hline not on purpose & unintentional \\
\hline of no use & useless \\
\hline
\end{tabular}

\section{Use Action Verbs — Avoid Overusing Nominalizations}

2.1 Use action verbs liberally. Action verbs are the life of your sentences because they express action. So use action verbs. And use the strongest action verbs that fit.

2.2 Avoid nominalizations when you can. A nominalization is a noun created from a verb. "Nominalization" is itself a nominalization. Here are more familiar examples:

\begin{tabular}{ll} 
VERB & NOMINALIZATION \\
\hline Discover & Discovery \\
\hline Impair & Impairment \\
\hline Allow & Allowance \\
\hline Agree & Agreement \\
\hline Decide & Decision \\
\hline Collide & Collision \\
\hline of no use & useless \\
\hline
\end{tabular}

2.3 When you use a nominalization, you bury in the noun the action expressed in the verb. Each verb you bury drains life from your sentences. 
2.4 Nominalizations require more words than verbs. For example, compare "I submitted an application" with "I applied." And nominalizations themselves are usually longer than their base verb. Compare "apply" with "application."

2.5 Nominalizations are often associated with the passive voice. Your writing should favor the active voice. Compare:

There was committee agreement.

with:

The committee agreed.

2.6 Although you should avoid using nominalizations as a rule, they are useful in some instances. These include:

a. When the nominalization is the subject that refers to previous text:

These arguments all depend on a single unproven fact.

The decision might have substantial consequences.

b. When the nominalization names what would be the object of its base verb:

I do not understand its meaning. (I do not understand what it means.)

We must examine the proposal. (We must examine what has been proposed.)

c. When the nominalization is a standard technical term:

The plaintiff opposed discovery. (Here, "discovery" refers to the methods for gathering information from the opposing party in litigation under court rules that permit and even compel information exchanges.)

\section{Prefer the Active Voice}

3.1 In an actively voiced sentence, the subject performs the action. In a passively voiced sentence, the subject is the recipient of the action.

Active: The court reversed the judgment.

Passive: The judgment was reversed. 
3.2 Passively voiced sentences often are vague because the actor need not be disclosed. The active voice is direct and clearly states the relationship between the subject and the action.

3.3 Passively voiced sentences require using a preposition to disclose the actor, thus making them longer than their active-voice counterpart. For example:

Active: The court reversed the judgment.

Passive: The judgment was reversed by the court.

3.4 Passively voiced sentences reverse the word order readers expect. Instead of actor, action, and object, the reader encounters object, action, and actor if the actor is identified at all.

3.5 Finally, passively voiced sentences frequently use nominalizations. The overuse of the passive voice and nominalizations can deaden your writing. "[B]y consistently using the active voice, you animate your style."19

3.6 The passive voice has uses, however. Here are several:

a. To avoid a long subject:

Judge Kozmenko was praised by her colleagues, dozens of lawyers who had appeared in her court, the court's administrative staff, and by numerous community leaders.

b. To avoid naming the actor or when the actor is unknown:

The victim was stabbed at 10:0o in the laboratory where he worked.

c. To shift focus to from the actor to another person when, for example, the actor's identity is unimportant:

On the witness stand, Dr. Foster admitted his diagnosis of the patient's cancer came too late. (We do not care who was questioning Dr. Foster.)

d. To place a strong element at the end of a sentence:

As he rose from his chair to leave, he was murdered.

e. To set a detached, abstract tone:

Justice denied is justice delayed.

19 Garner, The Elements of Legal Style, 42. 
f. To transition from one sentence to the next by beginning the second sentence with the last word in the first sentence:

John shot Mark. Mark was taken to the hospital an hour later.

3.7 Use the passive voice only when you have a reason to use it. Otherwise, use the active voice.

\section{Use Short Sentences}

4.1 Short sentences are easier to understand than long sentences. Long, complicated sentences often imply or reveal that you are not sure about what you want to say. If what you want to explain is complex, use short sentences to explain it, short sentences break the information into smaller, easier-to-digest units.

4.2 Express only one idea in each sentence. Express big ideas in several sentences.

4.3 Place the main idea before exceptions and conditions. You can depart from this rule when the exception can be expressed in a few words and seeing it first will help your readers.

4.4 Vary sentence length. You want to be punchy, not choppy, clipped, or angrysounding. But keep your average sentence length under 20 to 25 words.

4.5 As you edit your writing, look for "and" and "but" in the interior of your sentences. When you see "and" or "but," ask yourself if this would be a good place to end one sentence and begin another. Beginning a sentence with "and" or "but" is more than acceptable, many good writers liberally begin sentences with "and" and "but."

\section{Arrange Your Words with Care}

\section{A. Avoid Wide Gaps Between the Subject, the Verb, and the Object}

5.1 Readers of English-language sentences expect to see the subject, the verb, and the object in that order. They also expect to see these three elements close to the beginning of the sentence. They do not want to encounter wide gaps between any of these elements.

5.2 Especially troublesome for readers are wide gaps between the subject and the verb. Consider this sentence:

The Minister, after considering all documents submitted by the parties and, perhaps, making a personal inspection of the site, may nominate an arbitrator.

Seventeen words separate the subject from the verb in this sentence.

5.3 When the clause separating the subject from the verb is long, converting the clause to a separate sentence probably will be the best remedy. 
5.4 If the clause between the subject and the verb is short, moving it to the beginning or the end of the sentence probably will be the best remedy.

\section{B. When Necessary, Make a List-Parallelism}

5.5 Lists can be useful. They are a visually appealing way to present items in a series.

5.6 When you make a list, you must follow two rules: a punctuation rule and a grammar rule.

5.7 The punctuation rule requires the list to be separated from the first part of the sentence by a colon. Each item in the list must be separated from the item that follows it with a semi-colon. And the last item in the list must be preceded by an "and" or an "or," whichever is appropriate. Here is an example of a properly punctuated list in a sentence:

Admission to the Bar requires:

1. graduation from an ABA accredited law school;

2. proof of your good moral character and fitness to practice law; and

3. a passing score on the Bar examination.

5.8 The grammar rule known as "parallelism" applies any time you write items in pairs or in a series. Each item must be parallel in substance. If, for instance, the first item of a series is an activity, then every item in the series should be an activity. Each item also must be parallel in grammatical form. If the first item is a noun, for example, than the other item in the pair or the other item in the series must be a noun.

Here are examples of parallel and not parallel structures:

Parallel:

Anna likes hiking, swimming, and bicycling. (Three gerunds: "ing")

Not Parallel:

Anna likes hiking, swimming, and to ride a bicycle. (Two gerunds, one infinitive)

Parallel:

Anna likes to hike, to swim, and to ride a bicycle. (Three infinitives) Anna likes to hike, swim, and ride a bicycle. (It is okay to use only one "to" for all the items.)

Not Parallel: 
Anna likes to hike, swim, and to ride a bicycle. (Two infinitives, one verb not an infinitive)

Parallel:

The coach told the players that they should get a lot of sleep, that they should not eat too much, and that they should do some warm-up exercises before the game. (Three "that clauses")

Not Parallel:

The coach told the players that they should get a lot of sleep, that they should not eat too much, and to do some warm-up exercises before the game. (Two "that clauses," one clause not a "that clause")

\section{Put Modifying Words Close to What They Modify}

5.9 Modifying words are adjectives and adverbs that limit or qualify the sense of other words in a sentence. Modifying words affect the meaning of the words near them. Therefore, they should be put close to the words you want them to modify. One-word modifiers always must be placed next to the word or words they modify.

5.10 Avoid misplacing modifiers. Consider this sentence:

I know a man with a wooden leg named Smith.

Is "Smith" the wooden leg or the man?

5.11 Avoid "squinting" modifiers. A "squinting" modifier is a word that could modify the words on either side of it. Wydick gives us this example:

A trustee who steals dividends often cannot be punished.

He asks: "What does often modify? Does the sentence tell us that crime frequently pays? Or that frequent crime pays?" 20

5.12 Only" must be carefully controlled. Consider how "only's" placement affects the meanings of these sentences:

a. The judge is permitted to impose criminal sanctions only after the parties have a right to be heard.

b. The judge is permitted to impose only criminal sanctions after the parties have a right to be heard.

c. The judge is only permitted to impose criminal sanctions after the parties have a right to be heard. 
d. Only the judge is permitted to impose criminal sanctions after the parties have a right to be heard.

5.13 Avoid "dangling" modifiers. "Dangling" modifiers are words or phrases that modify the wrong phrase or something not in the sentence. Consider these sentences:

To determine whether to grant the motion, four factors must be considered.

Finding no error, the judgment was affirmed.

In the first sentence, only a court can grant a motion: "factors" cannot determine, consider, or do anything else. And the writer of the second sentence failed to say who affirmed the judgment. The sentences should be rewritten to say, respectively:

The court must consider four factors to determine whether to grant the motion.

Finding no error, the court affirmed the judgment.

Now consider this sentence:

Having tried hundreds of cases, the client had great confidence in her attorney.

This sentence could mean that the client was an attorney who had tried hundreds of cases. After all, attorneys occasionally are clients. Or it could be an example of a "dangling" modifier, as it would if its intended meaning is that the client's attorney has tried hundreds of cases. The sentences below correctly state the first and second possible ways of reading the original sentence:

The client, who had tried hundreds of cases, had great confidence in her attorney.

The client had great confidence in her attorney, who had tried hundreds of cases.

5.14 Avoid "nested" modifiers. "Nested" modifiers are modifying phrases within modifying phrases. Wydick offers this example:

A claim for exemption, which in the case of a dwelling that is used for housing not more than a single family shall not exceed $\$ 300,000$ or the fair market value, whichever is less, may be filed with the Administrator within 90 days after receipt of notice. 
Wydick eliminates the nested modifiers by breaking the sentence into two sentences:

A claim for exemption may be filed with the Administrator within 9o days after receipt of notice. The claim for a single family dwelling cannot exceed $\$ 300,000$, or the fair market value, whichever is less. $^{21}$

\section{Choose Your Words with Care}

\section{A. Use Concrete Words}

6.1 Sometimes lawyers must be vague. But when you do not need to be vague, do not be vague. Be specific and concrete instead.

6.2 Watch for these words in your writing:

aspect, phase, process, theme, consideration, manifestation, motivation, basis, situation, facet, character, degree, aspect, and circumstance.

Often these words add nothing. Worse, they can slow the reader=s pace and obscure the point. For example, compare:

Overcrowded prisons are an aspect of the prison violence problem.

with:

Prisoners attackeach other when they are stressed by the unavoidable, ever-present noise, smell, and tensions in an overcrowded prison.

6.3 Watch for words that express a relative condition or circumstance. To say the day was "cold" is likely to evoke different images among your readers. If the temperature matters, use a more vivid word than cold, "freezing," for example, or the actual temperature.

\section{B. Use Familiar Words}

6.4 Our job as legal writers is to communicate effectively. We write for our readers. Whenever possible, we must use words that our readers will understand. As Wydick puts it: "Given a choice between a familiar word and one that will send your reader groping for the dictionary, use the familiar word." 22

$21 \quad$ Wydick, Plain English for Lawyers, 51.

22 Wydick, Plain English for Lawyers, $5^{8 .}$ 
6.5 Garner agrees: "We shouldn't stifle a liberal use of the English vocabulary... But if you use a big word, assure yourself that you have done it because no other term will serve better in contextBnot because you want to teach your readers a new word." 23

6.6 "Even among familiar words, prefer the simple to the stuffy. Don't say termination if end will do as well. Don't use expedite for hurry, elucidate for explain, or utilize for use. Do not conclude that your vocabulary should shrink to preschool size. If an unfamiliar word is fresh and fits your need better than any other, use it, but don't utilize it." ${ }^{24}$

\section{About "Shall"}

6.7 Many who write about legal writing recommend against using "shall" when drafting statutes, rules, contracts, and other formal legal documents. "Shall" is litigated a lot. U. S. courts have interpreted it to mean "absolutely must," or "should," or "may." 25

6.8 Schiess says writers have two options, one of which is to substitute "must" for "shall." Here is the other option:

[U]se shall only to impose an obligation or duty on an actor (a person or entity that can perform duties) in the sentence. When used in this way, shall means "has a duty to." You can substitute that phrase for shall to test whether you have used shall correctly; if you have, the sentence will still make sense. This is a simplistic approach, but it works. For example, read these sentences from a child-support order, and notice which one does not work:

1. The Respondent shall pay $26 \%$ of his monthly net income to the Petitioner as child support.

2. Beginning in the year 2000, 26\% of all bonus checks shall be paid to Petitioner.

Sentence 1 uses shall correctly; sentence 2 does not. ${ }^{26}$

6.9 Garner says: "If you want to retain shall, then make sure that in each sentence in which it appears, it's the equivalent of must. Otherwise, cut it." 27

6.10 Instead of using "shall," Wydick offers these choices:

$$
\begin{array}{ll}
\text { must }= & \text { is required to } \\
\text { must not }= & \text { is required not to; is disallowed }
\end{array}
$$




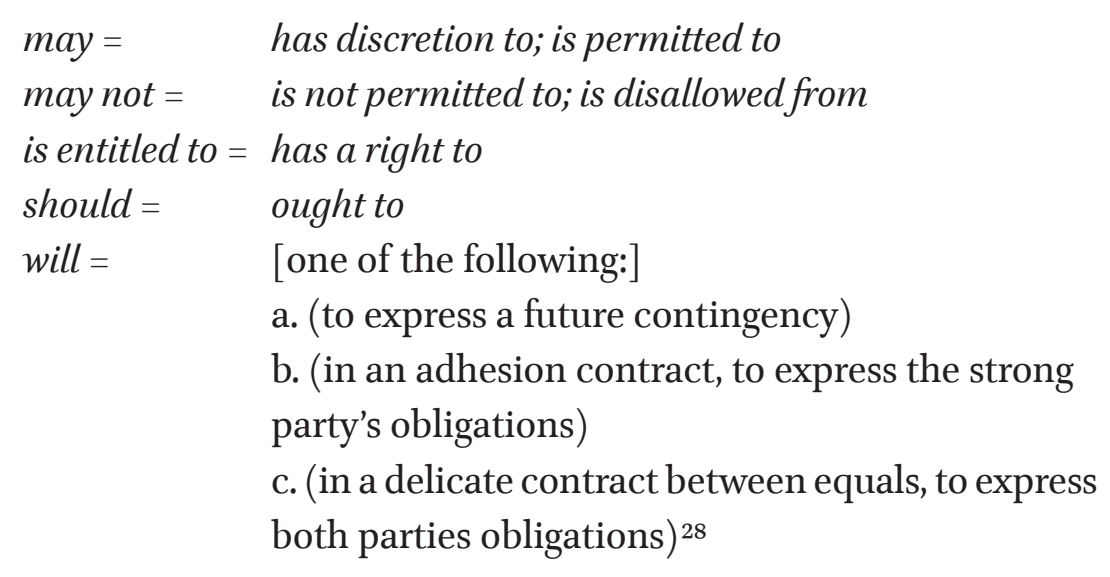

\section{Avoid Language Quirks}

\section{A. Avoid Elegant Variation}

7.1 Elegant variation is varying words to avoid using the same word twice or more in close proximity. Elegant variation works for literature and other writing genres. But " $t]$ he reader of a legal document is entitled to assume that a shift in terms is intended to signal a shift in meaning... Do not be afraid to repeat a word if it is the right word and if repeating it will avoid confusion." 29

7.2 Garner agrees with Wydick: "The problem is that if you use terms that vary slightly in form, the reader is likely to deduce that you intend the two forms to convey different senses... To a much greater extent than general style, legal style limits a single meaning to the single phrase." 30

\section{B. Avoid Multiple Negatives}

7.3 The following sentence uses double negatives:

Provided, however, that this license shall not become void unless the licensee's failure to provide such notice is unreasonable in the circumstances.

As Wydick points out and this sentence illustrates, double-negatives make "the reader's mind flip from yes to no to yes." ${ }^{31}$ Avoid double-negatives.

7.4 Double-negatives can be avoided by turning as many of the negatives as you can into positives. Thus, "it shall be unlawful to fail to stop at a red light" becomes "you must stop at a red light." 32

\footnotetext{
28 Wydick, Plain English for Lawyers, 64.

29 Wydick, Plain English for Lawyers, 70.

30 Garner, The Elements of Legal Style, 216-17.

$31 \quad$ Wydick, Plain English for Lawyers, 71.

$3^{2}$ Wydick, Plain English for Lawyers, 7-72.
} 


\section{Avoid Cosmic Detachment}

7.5 "Law is not just a bunch of dusty old precepts to be applied with humdrum objectivity... It is alive; blood courses through its veins... As often as not, to apply legal rules you must weigh, judge, and argue about human folkways and human foibles. And to do that well, you must have a heart... [I]n the end, the law must serve justice. Recognizing this fact is not a license to emote all over the page. But often in legal writing, sincerely expressing some feeling will work to your advantage." 33

7.6 "When you find yourself struggling to express a complex legal idea, remember to ask yourself the key question...: "Who is doing what to whom?" Bring those living creatures into your writing; make them move around and do things to each other. Suddenly abstraction will evaporate, and your writing will come alive... Remember, too, that your reader is the most important person in the universe or at least your reader thinks so. Don't be afraid to bring the readers into your sentences, and don't be afraid to call them you." ${ }^{34}$

\section{Use Strong Nouns and Verbs}

7.7 Writing statutes, rules, agreements, corporate documents, and the like calls for a different style of writing than writing arguments in briefs, settlement demands, and other documents where the goal is to persuade. When you are trying to persuade, use strong nouns and verbs. Prefer strong nouns and verbs over trying to prop up weak nouns with adjectives and weak verbs with adverbs.

7.8 As Garner puts it: "Think of the best single word instead of warming up a tepid one with a qualifier. For example:

Not this:

She was extremely interested in the book.

But this:

She was enthralled by the book.

Not this:

The customers were quite frightened by the gunman.

But this:

The customers were terrified by the gunman. ${ }^{35}$ 


\section{E. Avoid Sexist Language}

7.9 Wydick offers four suggestions for avoiding sexist language:

First, don't use expressions that implyvalue judgments based on sex. (For example, a manly effort, or a member of the gentle sex.) Second, use sex-neutral terms if you can do so without artificiality. (For example, use workers instead of workman and reasonable person instead of reasonable man. But don't concoct artificial terms like waitpersons to refer to servers in a restaurant.)

Third, use parallel construction when you are referring to both sexes. (For example, husbands and wives, not men and their wives, or President and Mrs. Watson, not President Watson and Mildred.) Fourth, try to avoid using a sex-based pronoun when the referent may not be of that sex. For instance, don't use he every time you refer to judges. You can resort to the clumsy phrase he or she in moderation, but you can often avoid the need by using one of the following devices:

- Omit the pronoun. For example, instead of "the average citizen enjoys his time on the jury," you can say "the average citizen enjoys jury duty."

- Use the second person instead of the third person. For example, instead of "each juror must think for herself," you can say, "as a juror, you must think for yourself."

- Use the plural instead of the singular. For example, instead of "each juror believes that he has done something worthwhile," you can say "all jurors believe that they have done something worthwhile."

- Repeat the noun instead of using a pronoun. For example, instead of "a juror's vote should reflect her own opinion," you can say "a juror's vote should reflect that juror's own opinion."

- Alternate between masculine and feminine pronouns. For example, if you use she to refer to judges in one paragraph, use he to refer to lawyers in the next paragraph. Be aware that this device may look artificial; further, if you are careless, you may perform a sex change on somebody in the middle of the paragraph.

- Use passive voice [but] ... only in desperation. ${ }^{36}$

\section{Conclusion}

In conclusion, plain English is about writing engagingly using the simplest, most straightforward way of saying what must be said. Put another way, plain English is 
interesting yet free of unnecessary adornments, whether they are fancy words that can be replaced by simple ones or unnecessary words that only impede the reader's progress and understanding. Boiled down to its core qualities, writing in plain English means writing clearly, concisely, and engagingly. Writing this way is satisfying to the writer and the reader. It serves the best interests of the legal profession and the fair and equitable judicial systems to which we all aspire.

\section{(2)}

Christopher R. Kelley is an Associate Professor of Law, University of Arkansas School of Law, Fayetteville, Arkansas, USA. He also is a non-resident Professor at the Taras Shevchenko National University of Kyiv Law Faculty. 